\title{
DETERMINATION OF PRODUCTION WELL'S COLLECTORS POROSITY \\ IN SOUTH-GEOLOGICAL AREA
}

. . троянецк я

G. E. Stroyanetskaya

юменский индустри льный университет, г. юмень

лючевые слов : коллекторы; скв жин ; р створ; керн; пористость; геофизические

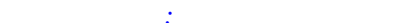

Key words: collectors; well; solution; core; porosity; geophysical researches; gas saturation

жно- еологической площ ди к 2006 году были пробурены скв. 267, 268, 271, 281,282 . сположены они в южной ч сти ерегового лицензионного уч стк и 3 ложены с целью эксплу т ции з лежей углеводородов в отложениях в л нжин . з скв. 267 поднят керн из пл ст 11 в интерв ле 3 479,1-3 498,4 м с выносом $98 \%$, из пл ст 10 - в интерв ле 3 415,2-3 439,2 м с выносом $97 \%$. ерн исследов лся. пределял сь его пористость, прониц емость. скв. 282 перфориров ны пл сты 10 и 11 в интерв л х $3267,5-3274$ м и $3330-3337$ м соответственно. результ те освоения из пл стов 10 и 11 получен приток г зоконденс тной смеси. 
кв жины бурились н глинистом р створе $(271,281,282)$, н полимерной промывочной жидкости с хлористо-к льциевой основой (268), н полимер-глинистом р ствоpe (267). дельное электрическое сопротивление ( ) промывочной жидкости ( ) в скв жин х сост вляло: 0,1 м м (267), 0,24 м м (268), 0,4 м м (271), 0,15 м м (281), 1 м м (282). дельный вес промывочной жидкости - от 1,12 до 1,15 г/см ${ }^{3}$, вязкость - 30-45 сек. омин льный ди метр скв жин в интерв ле пл стов 10 и $11-$ 0,216 м. емпер тур пл стов $-85-90^{\circ}$, д вление близко к гидрост тическому. л стовые воды гидрок рбон тно-н триевого тип с минер лиз цией 13 г/л.

интерв ле пл стов ${ }_{10}$ И ${ }_{11}$ в скв жин х выполнены общие и дет льные геофизические исследов ния. ет льные исследов ния включ ли: метод потенци лов собственной поляриз ции ( $)$, обычные микрозонды ( $\quad$ ), боковое к рот жное зондиров ние ( ), боковой к рот ж ( ), индукционный к рот ж ( ), боковой микрок рот ж ( ), двухзондовый нейтронный к рот ж ( ), г мм -к рот ж ( ), кустический к рот ж ( ), к вернометрию ( ), микрок вернометрию ( $)$, резистивиметрию. е проводился г мм -г мм плотностной к рот ж ( - ). двух скв жин х ди гр ммы не подлеж т количественной интерпрет ции из-з близости промывочной жидкости и пл стовой воды (скв. 268, 281). ривые сл бо р счленяют p зрезы скв жин. кривых против м ломощных уплотненных прослоев отмеч ются положительные прир щения при невысоких пок з ниях микрогр диент-зонд ( ) и микропотенци л-зонд ( ). ри тонкой корке против коллекторов кривые и изрез ны и предст влены чередов нием уч стков с совп д ющими и несовп д ющими пок з ниями и . р ссм трив емых скв жин х пок з ния в некоторых коллектор х соизмеримы с пок 3 ниями в ргиллит х (рис. 1). овышенные пок з ния обусловлены содерж нием к лиевых шп тов и кислых пл гиокл зов.

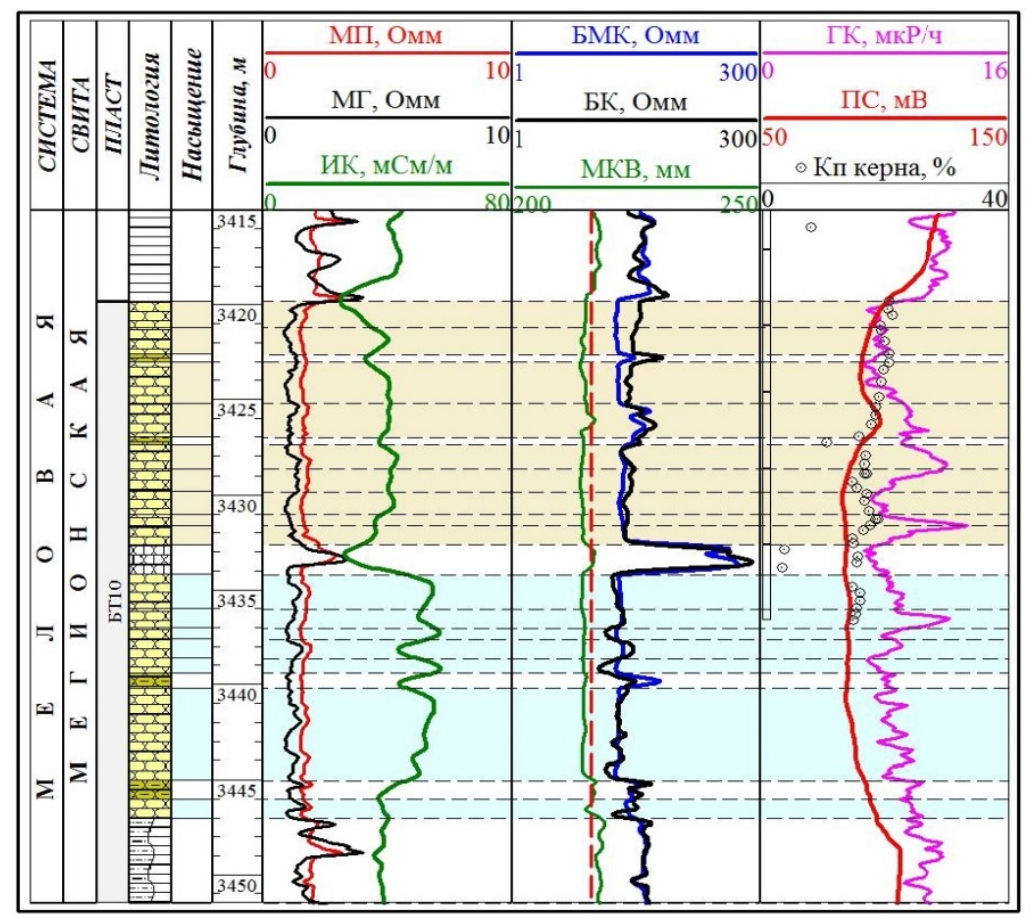

ис. 1. езульт ты геофизических исследов ний в интерв ле пл $\mathrm{cm} \quad{ }_{10}$ скв жины 267 жно- еологической площ,

ри выделении коллекторов при интерпрет ции геофизических исследов ний скв жин ( ) з основу приняты , , , , ст льные методы:

, , , использов лись в к честве дополнительных. н ч льном эт пе интерпрет ции при отсутствии информ ции о фильтр ционно-емкостных свойств х 
( $\quad$ ) керн возник ли з труднения при выделении коллекторов. оявление сведений о керн из скв. 267 позволило уточнить призн ки коллекторов по, , уст новить, что высокие пок з ния при положительных прир щениях н н личием в коллектор х к лиевых шп тов.

ри поисково-р зведочных р бот х определение коэффициент пористости ${ }_{n}$ коллекторов в пр ктике интерпрет ции проводится по д нным , , , - , и совместно с или , по комплексу методов , , или , , .

пределение ${ }_{n}$ по ( стостью, т кже функцион льным влиянием последней н относительную мплитуду

$\left(\propto_{n c}\right)$. о д нным скв. 267 жно- еологической площ ди для коллекторов пл стов 10 и $11^{3}$ висимость между коэффициентом пористости по керну ( $\left.\begin{array}{c}\text { керн } \\ \pi\end{array}\right)$ и $\propto_{n c}$ отсутствует, что исключ ет возможность н хождения ${ }_{n}$ по величине $\propto_{n c}$.

p фическое сопост вление н рисунке 2 величин ${ }_{n}^{\text {керн }}$ с относительным п р метром $\left(\propto_{2 \kappa}\right)$, р вным:

$\propto_{2 \kappa}=1-\mathrm{J}_{\text {гк }}$, где $\mathrm{J}_{\text {гк }}$ - двойной $\mathrm{p}$ зностный п $\mathrm{p}$ метр [1], пок з ло н личие 3 висимости между $\propto_{2 \kappa}$ и ${ }_{n}$ по керну. то позволяет определять по $\propto_{2 \kappa}$ коэффициент пористости $\left(\begin{array}{c}n \\ n\end{array}\right)$. р внение з висимости ${ }_{n}=f\left(\propto_{2 \kappa}\right)$ имеет следующий вид

$$
n=3,62 \propto_{2 \kappa}+14,8 \text {. }
$$

p внение (1) в соответствии с рисунком 2 позволяет определять ${ }_{n}$ коллекторов с погрешностью, в основном, до $2 \%$ по бсолютной величине и может использов ться для определения пористости прониц емых отложений в р ссм трив емых скв жин х.

ля н хождения коэффициент пористости по д нным изн ч льно предпол г лось использов ние ур внения среднего времени для неглинистых коллекторов [1]:

$$
{ }_{n}=\left(-\Delta_{c \kappa}\right) /\left(\Delta_{\phi л}-\Delta_{c \kappa}\right),
$$

где $\quad, \Delta_{c \kappa}, \Delta_{\phi л}-$ интерв льное время пробег упругой продольной волны по породе, скелету породы, флюиду. еличин попр вки $\left(\Delta_{n}\right)$ в ${ }_{n}$ н глинистость и г зон сыщенность отложений $\mathrm{p}$ вн $\mathrm{p}$ знице между ${ }_{n}$ и коэффициентом пористости по керну $\left(\begin{array}{c}\text { керн } \\ n\end{array}\right)$. ри н личии связи между $\Delta_{n}$ и к ким-то геофизическим п р метром, н пример $\propto_{2 \kappa}$, появляется возможность оценки $\Delta_{n}$ и следов тельно ${ }_{n}$ коллекторов. опост вление $\Delta_{n}$ с $\propto_{2 \kappa}$ пок з ло отсутствие з висимости между ними. оэтому д нный лгоритм н хождения ${ }_{n}$ не рекомендуется к применению.

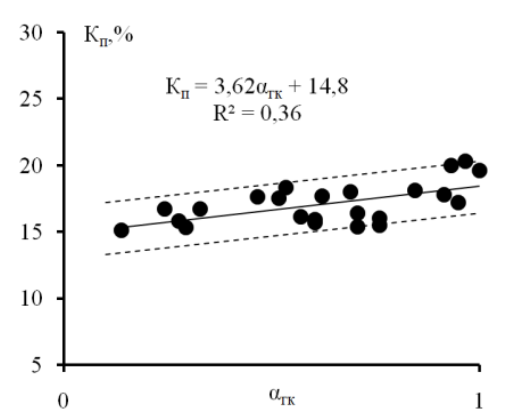

ис. 2. опост вление пористости по керну с относительной мплитудой $\propto_{2 к}$ по скв. 267 ля определения ${ }_{n}$ широкое применение получил формул [2]:

$$
{ }_{n}=\left(\left(-\Delta_{c \kappa}\right)\left(\propto_{n c}-1\right)^{0.5} /\right)^{0.5},
$$

где $\propto_{n c}$ позволяет учитыв ть глинистость коллекторов. оскольку в двух скв жин х сл бо дифференцирует $\mathrm{p}$ зрез, то целесообр зно глинистость учитыв ть по величине $\propto_{2 \kappa}$. огд (3) примет вид

$$
n=\left(\left(\quad-\Delta_{c \kappa}\right)\left(\propto_{2 \kappa}-1\right)^{0.5} /\right)^{0.5} \text {. }
$$

формуле (4) $\Delta_{c \kappa}$ можно принять 180 мкс/м и =0,19 по д нным ерегового месторождения. оскольку $\propto_{n c}$ и $\propto_{\text {гк }}-\mathrm{p}$ зные п р метры, которые не во всем ди п зоне коррелируются между собой и то, что (4) не учитыв ет г зон сыщенность коллекторов, то ${ }_{n}$, вычисленный по (4),будет отлич ть-

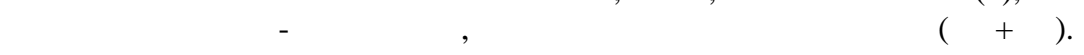

рис. 3 приведено гр фическое сопост вление ${ }_{n}(+)$ с $\propto_{2 \kappa}$. ежду ними н блюд ется з висимость. р внение этой з висимости имеет вид

$$
{ }_{n}(+)=8 \alpha-5,7 \text {. }
$$


итоге, н хождение $\quad{ }_{n}$ н основе формул (4) и (5) сводится к вычислению выр жения

$$
{ }_{n}=\left((\quad-180)\left(\propto_{2 \kappa}-1\right)^{0.5} / 0,19\right)^{0.5}-8 \alpha+5,7 \text {. }
$$
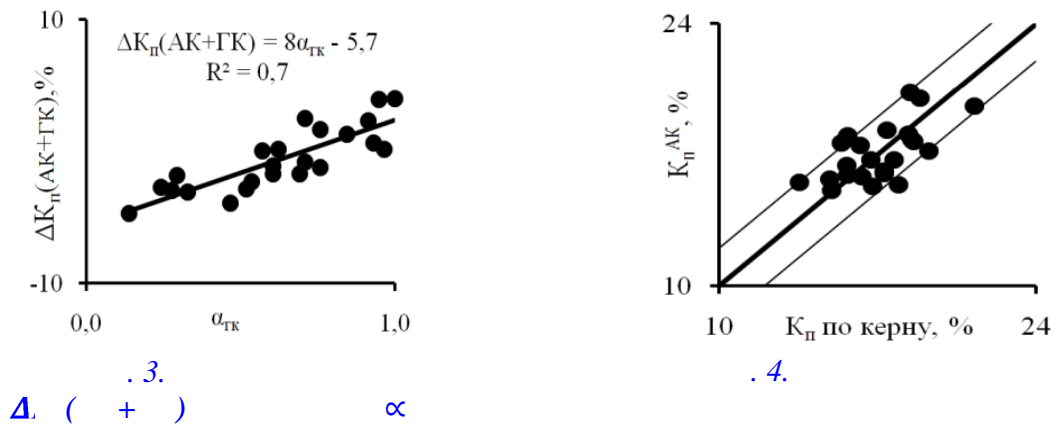

н чение ${ }_{n}$, полученное по формуле (6), в д льнейшем будет обозн ч ться $\left(\begin{array}{l}n \\ \text { ) }\end{array}\right.$ p фическое сопост вление п с керн, предст вленное н рис. 4, пок зыв ет, что от-

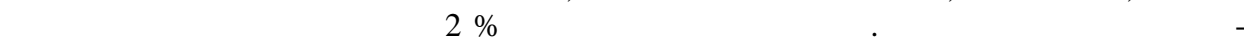
в ть выр жение (6) для определения пористости коллекторов.

хождение ${ }_{n}$ глинистых г зон сыщенных коллекторов по нейтронному к рот жу $\left({ }_{n}\right)$ осуществляется по формуле [1]:

$$
{ }_{n}=\mathrm{W}_{\Sigma}-\Delta \mathrm{W}+\Delta \mathrm{W}=\mathrm{W}_{\Sigma}-\Delta \mathrm{W}
$$

где $\mathrm{W}_{\Sigma}$ - сумм рный водородный индекс коллектор, $\Delta \mathrm{w}-$ водородный индекс твердой фр кции, $\Delta \mathrm{w}$ - попр вк в $\mathrm{W}_{\Sigma} \mathrm{H}$ влияние г 3 н пок з ния , $\Delta \mathrm{W}=\Delta \mathrm{W}-\Delta \mathrm{W}$.

спол г я зн чениями величин $\mathrm{W}_{\Sigma}$ и ${ }_{\Pi}^{\text {керн }}$, можно н йти их р зность $(\Delta \mathrm{W})$ и сопост вить ее с $\alpha$. еличин $\Delta \mathrm{W}$ является комплексной попр вкой (н глинистость и г зон сыщенность) в $\mathrm{W}_{\Sigma}$ при определении п по . ля коллекторов р ссм трив емых скв жин $\mathrm{W}_{\Sigma}$ определялось по методике двух опорных пл стов. рис. 5 предст влено сопост вление $\Delta \mathrm{W}$ с $\alpha$. $\mathrm{p}$ внение з висимости $\Delta \mathrm{W}$ от $\alpha$ имеет вид

$$
\Delta \mathrm{W}=-5,5 \alpha+6,4 \text {. }
$$

ри известных $\mathrm{W}_{\Sigma}$ и $\Delta \mathrm{W}$ величин ${ }_{n}=\mathrm{W}_{\Sigma}-\Delta \mathrm{W}$. $\mathrm{p}$ фик сопост вления ${ }_{n}$ с ${ }_{\pi}^{\text {керн }}$ н рис. 6 для коллекторов скв. 267 пок зыв ет, что их отличие, в основном, в предел х $2 \%$ по бсолютной величине, но имеются дв коллектор, для которых это отличие превыш ет $2 \%$ и достиг ет $3,7 \%$. нные коллекторы х р ктеризуются высоким коэффициентом г зон сыщенности ( г). ри высоких г д нн я методик оценки пне рекомендуется к использов нию.

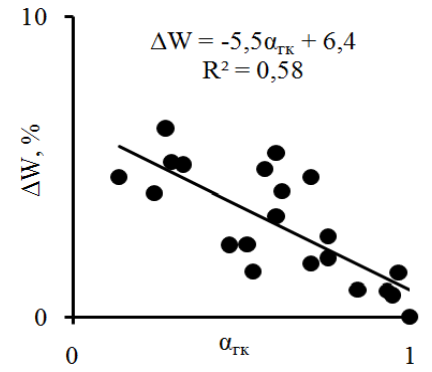

ис. 5. опост вление W $\boldsymbol{\alpha} \alpha$

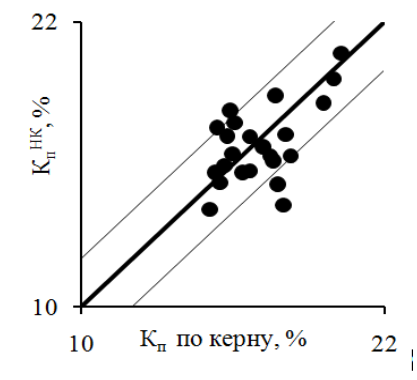

ис. 6. опост вление ${ }_{n} \quad{ }_{n}^{\text {керн }}$ 
оскольку г з ок зыв ет противоположное влияние н коэффициенты пористости, определенные по кустическому к рот жу (6) и нейтронному к рот жу (7), то средняя

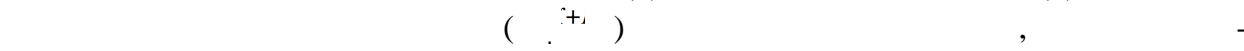
ности $n$ и ${ }_{n}$. р ктически н логичный результ т получ ется при использов нии формулы

$$
{ }_{n}={ }_{п}-\left({ }_{n}-{ }_{n}\right) /(1+),
$$

полученной из выр жения [3]

$$
{ }_{n}=n-(n-n) /(1+)
$$

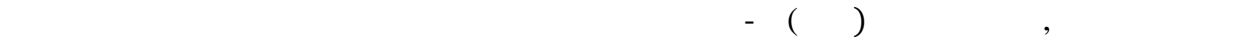
принят р вным 1,8 [3]. оэффициент пористости, определенный по формуле (9), в д льнейшем будет обозн ч ться п ${ }^{i+}$ рис. 7 предст влено гр фическое сопост в-

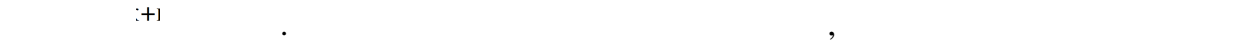

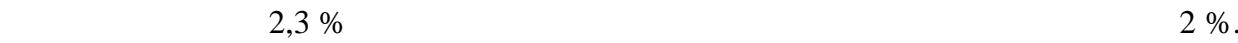

uc. 7. опост вление ${ }^{i+}{ }^{i+}{ }_{n}^{\text {керн }}$

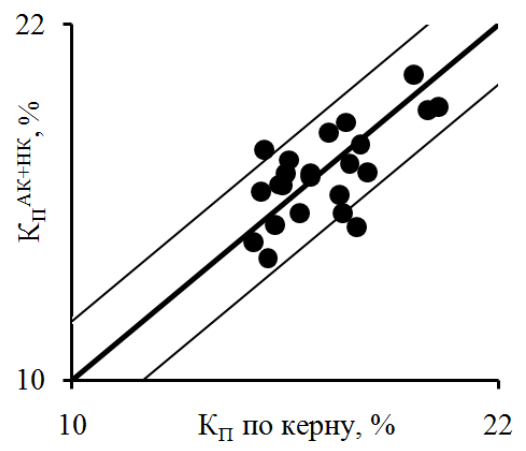

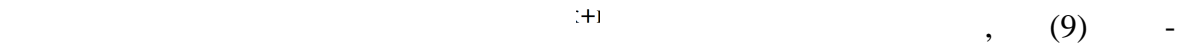
мендуется к пр ктическому применению. ри этом п н ходится (6), $n$ - по (7).

вьводы

1. ыделение коллекторов при вскрытии пл стов н полимерной промывочной жидкости с хлористо-к льциевой основой, н полимер-глинистом р створе с до 1 м м без отбор керн з труднительно. основу при выделении коллекторов необходимо приним ть , , к верногр мму. ст льные методы:

, использов ть в к честве дополнительных.

2. ценк пористости г зон сыщенных коллекторов возможн по д нным , по совместно с , по ур внению

$$
{ }_{n}={ }_{\Pi}-\left({ }_{n}-{ }_{n}\right) /(1+) \text {. }
$$

2. пределение пористости полимиктовых песч ников с использов нием кустического к рот ж по скорости. оменко . и др. сб. спользов ние м тери лов при комплексной интерпрет ции и подсчете 3 п сов нефти и г з - $\quad \therefore \quad$ ук $, 1986,-.95-97$.

3. пределение емкостных свойств и литологии пород в р зрез х нефтег зовых скв жин по д нным р дио ктивного и кустического к рот ж (н ст вление по интерпрет ции с комплектом п леток) / . . олов цк я, . . у улин, . . никеев и др. линин, $, 1984,110$ с.

ведения об вторе

троянецкя яин вгеньевн, ссистент $\kappa$ федры прикл дной геофизики, юменский индустрильный университет, тел. 8(3452)297403, e-mail: gis@tsogu.ru

Information about the author

Stroyanetskaya G. E., Assistant of Department of Applied Geophysics, Industrial University of Tyumen, Tyumen, tel.8(3452)297403, e-mail: gis@tsogu.ru
} 